\title{
ANALISIS REPURCHASE BEHAVIOR PADA CHANDRA SUPERSTORE TANJUNG KARANG
}

\author{
Benediktus Tedi Yulianto ${ }^{1}$, Ardiyansyah Amri² \\ Program Studi Manajemen, Sekolah Tinggi IImu Ekonomi, Gentiaras Bandar Lampung \\ Email : amridiansyah@gmail.com²
}

\section{ABSTRACT}

This Research aims to find how much influence between the perceptions of prices by consumers on consumer repurchase behavior. In this study analyze the problems and prove the hypothesis by using the method of observation with quantitative approach survey, the data used is primary data is data that researchers obtain directly in the field. The result of significant level shows $50,53 \%$ and based on calculation of coefficient of determination $\left(R^{2}\right)$ is relatively small that is equal to 0,207 . Means that price perceptions affect $20.7 \%$ of repurchase behavior.

Suggestion of improvement, regarding the clean and neat shopping place, to be repaired so that consumers feel satisfied with the perception of quality received in accordance with the cost incurred in shopping at Chandra Superstore Tanjung Karang Bandar Lampung.Suggested improvements, enhance the reputation of shopping facilities that make consumers more comfortable shopping that will make consumers more often re-shop at Chandra Superstore Tanjung Karang Bandar Lampung and rechoose a strategic location in the development.

Keywords: Perception of price, Purchase decision process, Repurchase behavior

\section{PENDAHULUAN}

\subsection{Latar Belakang}

Chandra Superstore perlu mengantisipasi perkembangan ekonomi yang semakin kompetitif dengan melakukan strategi yang tepat agar tidak tersisih dalam persaingan.

Tabel 1.

Hasil Survey Pra Riset Jumlah Pengunjung Dan Jumlah Pembeli Chandra Superstore Tanjung Karang

\begin{tabular}{ccccc}
\hline No & Waktu & $\begin{array}{c}\text { Jumlah } \\
\text { Pengunjung } \\
\text { (Pintu Masuk) }\end{array}$ & Waktu & $\begin{array}{c}\text { Jumlah Pembeli } \\
\text { (Pintu Keluar) }\end{array}$ \\
\hline 1 & $11.02-11.07$ & 47 & $11.09-11.14$ & 14 \\
2 & $11.15-11.20$ & 44 & $11.21-11.26$ & 31 \\
3 & $11.27-11.32$ & 37 & $11.33-11.38$ & 16 \\
\hline & Jumlah & 128 & & 61 \\
\hline & Rata-rata & 42,67 & & 20,34 \\
\hline
\end{tabular}

Sumber : Data diolah, 2018

Peneliti melihat permasalahan yang terjadi yakni jumlah pengunjung yang berbelanja lebih sedikit dibanding jumlah pengunjung yang datang. Berikut peneliti tampilkan data tersebut dalam bentuk diagram, serta penjelasan presentase pengunjung yang masuk di area Chandra Superstore dan yang berbelanja diukur dengan pengunjung yang membayar barang belanjaan di pintu keluar kasir. 
Gambar 1

Grafik Perbandingan Jumlah Pengunjung Dengan Jumlah Pembeli Chandra Superstore

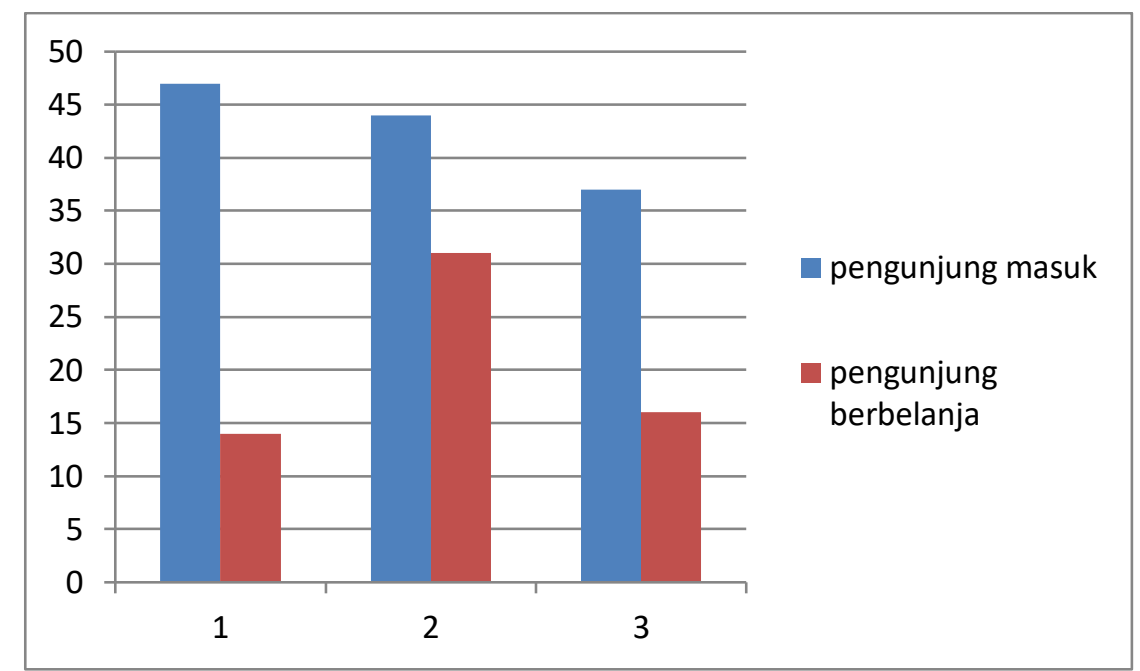

Sumber : Data diolah, 2018

Berdasarkan data pada grafik di atas diketahui bahwa pada data lima menit pertama hanya $29,78 \%$ dari jumlah pengunjung yang berbelanja sedangkan pada data lima menit kedua terjadi peningkatan yakni sebesar $70,45 \%$ pengunjung berbelanja, dan yang terakhir terjadi penurunan dari data yang kedua yakni 43,24\% pengunjung berbelanja, kemudian jika di rata-rata kan ada 47,65\% pengunjung berbelanja di Chandra Superstore. Dari data perbandingan jumlah pengunjung dan jumlah pembeli tersebut peneliti menemukan masalah bahwa $52,35 \%$ pengunjung Chandra Superstore tidak berbelanja.

Dari data di atas dapat terlihat bahwa konsumen yang pernah berbelanja di Chandra Superstore Tanjung Karang Bandar Lampung rata-rata menjawab persepsi harga sedang. Artinya konsumen berfikir bahwa produk yang dijual tidak mahal dan murahan.

\subsection{Perumusan Masalah}

Apakah terdapat pengaruh persepsi harga terhadap perilaku repurchase behavior di Chandra Superstore Tanjung Karang Bandar Lampung?

\subsection{Tujuan Penelitian}

Untuk membuktikan besarnya pengaruh persepsi harga terhadap perilaku repurchase behavior di Chandra Superstore Tanjung Karang Bandar Lampung.

\section{TINJAUAN PUSTAKA}

\subsection{Persepsi Harga}

Menurut Peter dan Olson (2010) "Price perception concern how price information is comprehended by consumers and made meaningful to them. "Artinya bahwa bagaimana informasi harga dapat dipahami oleh pelanggan dan membuat berarti bagi pelanggan. Menurut Malik dan Yaqoob (2012) persepisi harga adalah "the process by which consumers interpret price and attribute value to a good or service proses", yang berarti sebuah proses dimana pelanggan menafsirkan nilai harga dan atribut ke barang atau pelayanan yang diinginkan

Menurut Campbell pada Cockril dan Goode (2010) menyatakan bahwa "persepsi harga merupakan faktor psikologis dari berbagai segi yang mempunyai pengaruh yang penting dalam reaksi konsumen kepada harga. Karena itulah persepsi harga menjadi alasan mengapa seseorang membuat keputusan untuk membeli."

Menurut Lichtenstein et al pada Munnukka (2008) menyatakan bahwa "persepsi harga berhubungan dengan level penerimaan harga pada konsumen yang juga lebar dari batas penerimaan harga. Konsumen melihat harga yang dikategorikan sebagai tinggi, rendah atau adil, dalam kaitannya dengan nilai dirasakan atau pengalaman yang dirasakan ketika menggunakan produk." 
Freddy Rangkuti (2008) menyatakan bahwa "persepsi harga adalah biaya relatif yang harus konsumen keluarkan untuk memperoleh produk atau jasa yang ia inginkan". Menurut Freddy Rangkuti dalam Leonardo dan Erwan (2012) dalam persepsi mengenai harga diukur berdasarkan persepsi pelanggan yaitu dengan cara menanyakan kepada pelanggan variabel-variabel apa saja yang menurut mereka paling penting dalam memilih sebuah produk.

Persepsi harga dibentuk oleh 2 dimensi utama, yaitu 1) Persepsi kualitas diaman konsumen cenderung lebih menyukai produk yang harganya mahal ketika informasi yang didapat hanya harga produknya saja. 2) Persepsi biaya yang dikeluarkan, konsumen menganggap bahwa harga merupakan biaya yang dikeluarkan untuk mendapatkan sebuah produk. Tetapi konsumen mempunyai persepsi yang berbeda-beda terhadap biaya yang dikeluarkan meskipun untuk produk yang sama.

Hal ini tergantung situasi dan kondisi yang dialami konsumen. Lebih lanjut Nagle \& Hogan (2006) menambahkan 2 dimensi yang membentuk persepsi harga pada konsumen, yaitu 1) persepsi perbedaan harga yakni evaluasi dari konsumen terhadap perbedaan harga yang ditawarkan terhadap harga dasar yang telah diketahui oleh konsumen. 2) Harga referensi, harga yang dibentuk oleh pelanggan berdasarkan dua hal, antara lain: harga menurut pengalaman pelanggan tersebut (internal reference price) dan harga yang diinformasikan oleh orang lain atau iklan di luaran yang dilihat oleh pelanggan (external reference price).

Dimensi persepsi harga seperti persepsi kualitas terdiri dari persepsi citra merek dan persepsi citra toko. Dimensi persepsi biaya yang dikeluarkan terdiri dari persepsi terhadap kewajaran harga dan persepsi terhadap ekuitas merek dapat menggambarkan efek harga untuk produk keterlibatan tinggi atau situasi pembelian.

\subsection{Repurchase Behavior}

Menurut teori Fornel dalam jurnal Sahin A, Zehir C dan Kitapci H (2012), Repurchase Intentions mengacu pada kemungkinan seseorang dalam menggunakan kembali suatu merek di masa depan. Repurchase Intentions merupakan salah satu perilaku dalam melakukan proses keputusan pembelian.

Menurut teori Suryani dalam jurnal Rizal (2013), melakukan pembelian secara teratur atau berulang adalah pelanggan yang telah melakukan pembelian suatu produk sebanyak dua kali atau lebih.

Sedangkan menurut teori SchiffmanKanuk dalam jurnal Rizal (2013), ada dua tipe pembelian yaitu pembelian untuk percobaan dan pembelian ulang. Pembelian percobaan merupakan tahap penyelidikan dari perilaku pembelian dimana konsumen berusaha mengevaluasi produk dengan mencoba. Jika suatu produk dibeli dengan percobaan ternyata memuaskan atau atau lebih memuaskan dari produk sejenis yang sebelumnya digunakan, maka konsumen berkeinginan untuk membeli ulang (repurchase behavior).

Menurut teori Yi dan Suna dalam jurnal Sahin A, Zehir C dan Kitapci H (2012), repurchase behavior dapat diukur melalui dua indikator yaitu :

1) Repeat purchase intention : Repeat purchase intention adalah pembelian yang dilakukan dalam intensitas yang berulang. Dalam penelitian ini Repeat purchase intention adalah kondisi dimana konsumen memiliki tingkat intensitas akan kedatangan kembali ke Chandra Superstore.

2) Repurchase probability : Repurchase probability adalah suatu kemungkinan terjadinya pembelian kembali. Dalam penelitian ini maka Repurchase probability adalah kemungkinan yang dihadapi konsumen untuk datang kembali ke Chandra Superstore.

\subsection{Hipotesis}

Diduga persepsi harga berpengaruh terhadap perilaku repurchase behavior di Chandra superstore Tanjung Karang Bandar Lampung. 


\section{METODOLOGI PENELITIAN}

\subsection{Jenis Penelitian}

Penelitian ini menganalisis permasalahan dan membuktikan hipotesis menggunakan metode kuantitatif. Metode yang digunakan adalah metode korelasional dan survey. Gay dalam Sukardi (2008) menyatakan penelitian korelasi merupakan salah satu bagian penelitian ex-post facto karena pada umumnya peneliti tidak memanipulasi keadaan variabel yang ada dan langsung mencari adanya suatu hubungan dan tingkat hubungan variabel yang dinyatakan dalam koefisien korelasi. Tempat penelitian berada di Chandra Superstore Tanjungkarang Bandar Lampung pada bulan Mei s.d. Juni 2018 dengan responden konsumen Chandra Superstore Tanjungkarang Bandar Lampung.

\subsection{Populasi Dan Sampel}

Dalam penelitian ini populasi umum mencakup seluruh konsumen yang berkunjung ke Chandra Superstore Tanjungkarang, sedangkan populasi targetnya adalah konsumen yang masuk kedalam Chandra Superstore Tanjungkarang. Sampel dalam penelitian ini adalah 100 orang konsumen yang berbelanja di Chandra Superstore Tanjungkarang.

Sugiyono (2013) menjelaskan Nonprobability Sampling adalah teknik pengambilan sampel yang tidak memberi peluang/kesempatan sama bagi setiap unsur atau anggota populasi untuk dipilih menjadi sampel. Teknik sampel yang digunakan dalam penelitian ini adalah teknik snowball sampling. Snowball Sampling dalah teknik penentuan sampel yang mula-mula jumlahnya kecil lalu kemudian semakin membesar. Dalam penentuan sampel, pertama-tama dipilih satu atau dua orang, tetapi karena dengan dua orang ini belum merasa lengkap terhadap data yang diberikan, maka peneliti mencari orang lain yang dipandang mengetahui dan dapat melengkapi data yang diberikan oleh dua orang sebelumnya

\subsection{Teknik Pengumpulan Data}

Dalam penelitian ini teknik yang digunakan adalah observasi dan kuisioner.
Data yang diperlukan dalam penelitian ini meliputi Sugiono, (2010 : 230) Data Primer, yakni data yang diperoleh langsung melalui penelitian, baik melalui penggunaan kuesioner maupun wawancara. Data skunder, data yang diperoleh dari teknik dokumentasi dengan memanfaatkan sumber-sumber yang berkaitan dan dapat mendukung obyek yang akan diteliti. Teknik pengumpulan data dalam penelitian ini adalah dengan; a) kuesioner yaitu daftar pertanyaan disebarkan secara tertutup dimana setiap pertanyaan sudah disediakan altenatif jawaban b) Studi Kepustakaan dan Dokumentasi dilakukan dengan cara melihat dan mempelajari berbagai sember bahan bacaan.

\subsection{Teknik Analisis Data \\ 1. Analisis Kuantitatif}

Menurut Sugiyono, teknik penelitian kuantitatif juga dapat diartikan sebagai suatu metode penelitian dengan landaskan pada filsafat positivisme, digunakan untuk meneliti populasi atau sampel. Data kuantitatif sendiri kaitanya sangat erat dalam proses penelitian kuantitatif. Penelitian kuantitatif sendiri adalah penelitian ilmiah dengan sistem yang sistematis dan tujuanya adalah untuk mengembangkan nilai-nilai matematis terhadap suatu fenomena yang terjadi di dunia.

a. Uji Validitas, adalah Uji ketepatan atau ketelitian suatu alat ukur dalam mengukur apa yang sedang ingin diukur. Dalam pengertian yang mudah dipahami, uji validitas adalah uji yang bertujuan untuk menilai apakah seperangkat alat ukur sudah tepat mengukur apa yang seharusnya diukur. Ghozali (2009) menyatakan bahwa uji validitas digunakan untuk mengukur sah, atau valid tidaknya suatu kuesioner. Suatu kuesioner dikatakan valid jika pertanyaan pada kuesioner mampu untuk mengungkapkan sesuatu yang akan diukur oleh kuesioner tersebut.

b. Uji realibilitas, menurut Sugiono (2005), reliabilitas adalah serangkaian pengukuran atau serangkaian alat ukur yang memiliki konsistensi bila pengukuran yang dilakukan dengan alat ukur itu dilakukan secara 
berulang Rumus Uji Reliabilitas Teknik Belah Dua dilakukan dengan cara membagi tes menjadi dua bagian yang relatif sama (banyaknya soal sama), sehingga masing-masing test mempunyai dua macam skor, yaitu skor belahan pertama (awal / soal nomor ganjil) dan skor belahan kedua (akhir / soal nomor genap). Koefisien reliabilitas belahan tes dinotasikan dengan r1/2 1/2 dan dapat dihitung dengan menggunakan rumus yaitu korelasi angka kasar Pearson. Selanjutnya koefisien reliabilitas keseluruhan tes dihitung menggunakan formula SpearmanBrown, yaitu:

$$
\mathrm{r}_{11}=\frac{2 \mathrm{r}_{\frac{11}{2} \frac{1}{2}}}{1+\mathrm{r}_{\frac{11}{2} \frac{1}{2}}}
$$

Sumber : Arikunto (2006)

Ghozali (2009) menyatakan bahwa reliabilitas adalah alat untuk mengukur suatu kuesioner yang merupakan indikator dari peubah atau konstruk. Suatu kuesioner dikatakan reliabel atau handal jika jawaban seseorang terhadap pernyataan adalah konsisten atau stabil dari waktu ke waktu.

c. Uji T, dikenal juga dengan uji parsial yaitu untuk menguji bagaimana pengaruh masing-masing variabel bebasnya secara sendiri-sendiri terhadap variabel terikatnya. Uji ini dapat dilakukan dengan mambandingkan $t$ hitung dengan $t$ tabel atau dengan melihat kolom signifikansi pada masing-masing t hitung.

d. Uji $\mathbf{R}^{\mathbf{2}}$ (koefisien determinasi)

$\mathrm{R}^{2}$ adalah perbandingan antara variasi $Y$ yang dijelaskan oleh $X$ secara bersama-sama dibanding dengan variasi total $Y$. Jika selain $X$ semua variabel di luar model yang diwadahi dalam $\mathrm{E}$ dimasukkan ke dalam model, maka nilai $\mathrm{R}^{2}$ akan bernilai 1. Ini berarti seluruh variasi $Y$ dapat dijelaskan oleh variabel penjelas yang dimasukkan ke dalam model.

Tidak ada ukuran yang pasti berapa besarnya $R^{2}$ untuk mengatakan bahwa suatu pilihan variabel sudah tepat. Jika $R^{2}$ semakin besar atau mendekati 1 , maka model makin tepat. Untuk data survai yang berarti bersifat cross section data yang diperoleh dari banyak responden pada waktu yang sama.

e. Regresi, Menurut Kurniawan (2008) regresi linier adalah metode statistika yang digunakan untuk membentuk model hubungan antara variabel terikat (dependen; respon; Y) dengan satu atau lebih variabel bebas (independen, prediktor, X). Uji regresi peneliti butuhkan untuk menguji seberapa besar pengaruh sebab-akibat antara variabel independen (Persepsi Harga) dengan variabel dependen (Repurchase Behavior). Model persamaan regresi linier sederhana sebagai berikut: $\mathrm{Y}=\mathrm{a}+\mathrm{bX}+\mathrm{e}$

\section{HASIL ANALISIS PENELITIAN}

a. Uji Validitas

Uji validitas diujikan pada 40 responden yang dilakukan dengan menggunakan teknik snowball. Kriteria pengujian apabila memiliki tingkat korelasi signifikan antara $1 \%-5 \%$, maka pengukuran dikatakan valid dan sebaliknya apabila memiliki tingkat korelasi signifikan lebih dari 5\% dinyatakan tidak valid. Berdasarkan hasil pengolahan, data pada instrumen penelitian hal ini angket dijelaskan dalam tabel sebagai berikut.

Tabel 2.

Hasil uji Validitas kuisioner Persepsi Harga (X)

\begin{tabular}{ccl}
\hline Variabel & Validitas & Hasil \\
\hline Butir Pertanyaan 1 & 0,735 & Valid \\
Butir Pertanyaan 2 & 0,807 & Valid \\
Butir Pertanyaan 3 & 0,617 & Valid
\end{tabular}




$\begin{array}{lll}\text { Butir Pertanyaan 4 } & 0,591 & \text { Valid } \\ \text { Butir Pertanyaan 5 } & 0,620 & \text { Valid } \\ \text { Butir Pertanyaan 6 } & 0,694 & \text { Valid } \\ \text { Butir Pertanyaan 7 } & 0,608 & \text { Valid } \\ \text { Butir Pertanyaan 8 } & 0,792 & \text { Valid } \\ \text { Butir Pertanyaan 9 } & 0,704 & \text { Valid } \\ \text { Butir Pertanyaan 10 } & 0,630 & \text { Valid } \\ \text { Butir Pertanyaan 11 } & 0,403 & \text { Valid } \\ \text { Butir Pertanyaan 12 } & 0,566 & \text { Valid }\end{array}$

Sumber : Data diolah 2018

Tabel 3.

Hasil Uji Validitas Kuisioner Repurchase Behavior (Y)

\begin{tabular}{ccc}
\hline Variabel & Validitas & Hasil \\
\hline Butir pertanyaan 1 & 0,615 & Valid \\
Butir pertanyaan 2 & 0,561 & Valid \\
Butir pertanyaan 3 & 0,719 & Valid \\
Butir pertanyaan 4 & 0,773 & Valid \\
Butir pertanyaan 5 & 0,641 & Valid \\
Butir pertanyaan 6 & 0,785 & Valid \\
\hline
\end{tabular}

Sumber : Data diolah 2018

\section{b. Uji Reliabilitas}

Pada pengujian reliabilitas instrumen digunakan rumus alpha cronbach dengan membandingkan nilai alpha cronbach dengan nilai 0,6. Jika nilai alpha cronbach $>0,6$ berarti instrumen tersebut reliable dan sebaliknya apabila nilai alpha cronbach $<0,6$ berarti instrumen tersebut tidak reliable.

Tabel 4.

Hasil Uji Reliabilitas

\begin{tabular}{cccc}
\hline Variabel & Koefisien Alpha Croncbach & Hasil & Kesimpulan \\
\hline Persepsi Harga $(\mathrm{X})$ & 0,862 & alpha $>0,6$ & Reliable \\
\hline Repurchase Behavior $(\mathrm{Y})$ & 0,773 & alpha $>0,6$ & Reliable \\
\hline
\end{tabular}

Sumber : Data diolah, 2018

Berdasarkan hasil uji reliabilitas pada tabel 4.3, maka instrumen yang digunakan peneliti pada penelitian ini adalah reliable. Hal ini ditunjukan dengan besarnya nilai alpha, pada item pertanyaan pada kuesioner. Koefisien cronbach's alpha untuk masingmasing item pertanyaan $\geq 0,5$ artinya cronbach's alpha dapat diterima (acceptable) dengan kata lain jawaban responden terhadap pertanyaan yang digunakan untuk mengukur persepsi harga dan Repurchase Behavior adalah konsisten dan dapat dipercaya (reliable).

\section{c. Analisis Regresi Linier}

Dari hasil olah data uji simple regression terdapat beberapa hasil analisis data dan dijelaskan sebagai berikut : 
ISSN 2086-9592

Tabel 5.

Persamaan garis Regresi dan Uji t Coefficients

\begin{tabular}{ccccccc}
\hline \multirow{2}{*}{ Model } & \multicolumn{2}{c}{$\begin{array}{c}\text { Unstandardized } \\
\text { Coefficients }\end{array}$} & $\begin{array}{c}\text { Standardized } \\
\text { Coefficients }\end{array}$ & \multirow{2}{*}{ T } & Sig. \\
\cline { 3 - 5 } & B & Std. Error & Beta & & \\
\hline \multirow{2}{*}{1} & (Constant) & 6,130 & 2,582 & & 2,374 &, 020 \\
& Persepsi harga &, 281 &, 056 &, 455 & 5,053 &, 000 \\
\hline
\end{tabular}

a. Dependent Variable: repurchase behavior

Sumber : Data diolah, 2018

Tabel selanjutnya menggambarkan persamaan regresi yaitu $Y=6,130+0,281 X$.

Kemudian penulis menyimpulkan hasil penelitian dalam gambar sebagai berikut :

Gambar 2.

Full model penelitian

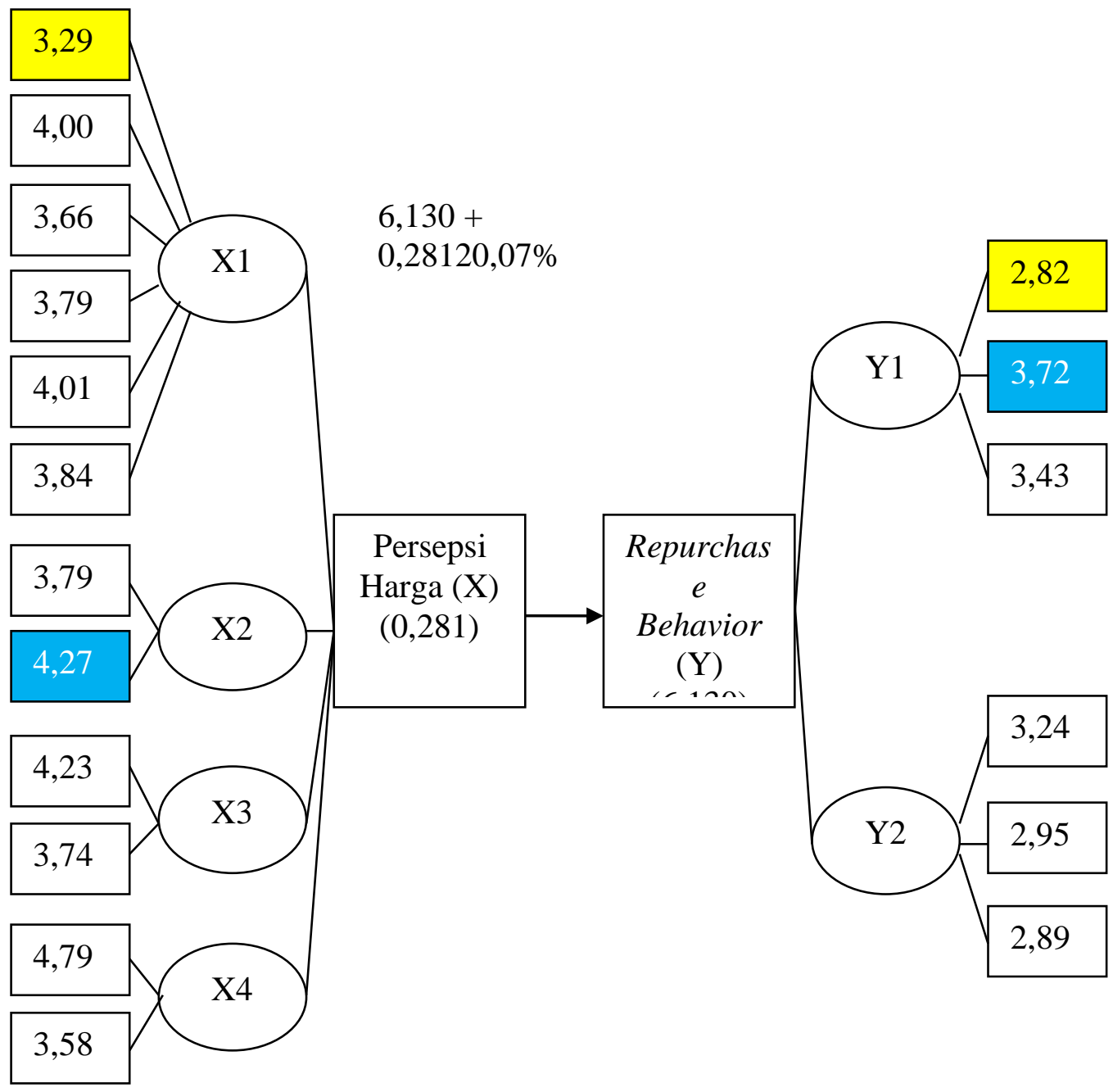

Sumber : Data dirangkum, 2018

Berdasarkan gambar tersebut dapat dijelaskan bahwa perilaku repurchase behavior dipengaruhi oleh persepsi harga terutama pada persepsi biaya yang dikeluarkan. Halis peelitian 
ini membuktikan hipotesis alternatif diterima dan hipotesis objektif ditolak.

\section{SIMPULAN DAN SARAN}

\subsection{Simpulan}

Pengaruh variabel $X$ terhadap $Y$ sebesar $20,7 \%$, yang berarti pengaruhnya kecil, kemudian $79,3 \%$ dipengaruhi oleh faktor lain yang tidak diikutsertakan dalam penelitian ini. Meskipun pengaruhnya kecil tetapi hipotesis diterima disebabkan signifikan. Untuk peneliti selanjutnya maka perlu dilakukan penelitian dengan menggunakan variabel diluar persepsi harga seperti, kualitas pelayanan, fasilitas, harga, kualitas produk, lokasi belanja dan lainlainya. Penulis dapat menarik kesimpulan bahwa benar terdapat pengaruh persepsi harga terhadap perilaku Repurchase Behavior pada Chandra Ssuperstore Tanjung karang bandar Lampung.

\subsection{Saran}

Pesepsi harga menjadi salah satu faktor yang mempengaruhi keputusan pembelian, hal ini terbukti dari hasil analisis yang sudah peneliti bahas dalam bab sebelumnya, oleh karena itu Chandra Superstore Tanjung Karang perlu menerapkan kebijakan agar dapat membuat aspek persepsi harga lebih baik sehingga dapat mencapai keputusan pembelian ulang. Mengingat adanya pengaruh antara persepsi harga terhadap perilaku Repurchase behavior, maka saran yang dapat diberikan oleh peneliti sebagai berikut :

\section{DAFTAR PUSTAKA}

Arikunto. (2010). Prosedur Penelitian: Suatu Pendekatan Praktek. Jakarta: Rineka Cipta.

Cockrill, Antje., Mark M.H. Goode. Perceived Price And Price Decay In the DVD Marke. The Journal of Product And Brand Management, 19 (5) 2010.

F. Tjiptono \& G. Chandra. Service, Quality \& Satisfaction. ANDI. Yogyakarta. 2011.

Ghozali, Imam. 2009. "Aplikasi Analisis Multivariate dengan Program SPSS ". Semarang : UNDIP.
https://id.wikipedia.org/wiki/Chandra Super St ore_Tanjung_Karang 30/04/2018, 13.00, Lampung

Huang,Yu-Kai. The Effect of Airline Service Quality on Passengers Behavioural Intentions Using SERVQUAL Scores: A TAIWAN Case Study.. Journal of the Eastern Asia Society for Transportation Studies, Vol.8, 2009

Indah Suryani. 2013. Pengaruh Penggunaan Informasi Akuntansi Manajemen Dan Desentralisasi Terhadap Kinerja Manajerial. e-Jurnal BINAR AKUNTANSI Vol.2 No.1. ISSN 23031522.

Leonardo, Ricky., Erwan. 2012. Analisis Pengaruh Kualitas Produk, Ekuitas Merek dan Persepsi Harga Terhadap Keputusan Pembelian Konsumen (Study Kasus : PT. Lung Xiang Indonesia). Undergraduate Thesis, Library Bina Nusantara, http://library.binus.ac.id/Collections/eth esis_detail/2012-2- 00128-MN.

Malik,\&Yaqoob,\& Aslam. The Impact of Price Perception, Service Quality, And Brand Image On Custumer Loyalty (Study Of Hospitality Industry In Pakistan Interdisciplinary, Journal Of Contempory Research In Business Vol 4, No. 5. 2012.

Munnukka, J. 2008. Customers' Purchase Intentions as a Reflection of Price Perception.From: $\quad$ http://doi.org/ 10.1108/10610420810875106. Journal of Product \& Brand Management, Volume17, Number 3, Pages 188-196.

Nagle, T.T and Hogan, J,The Strategy And Tactics Of Pricing, A Guide To Growing More Profitably Prentice Hall. (2006).

Peter, Paul J., Jerry C. Olson. Consumer Behavior \& Marketing Strategy. 9th Edition. McGraw Hill. 2010.

Rangkuti, Freddy. ((2009). Strategi Promosi yang Kreatif dan Analisis Kasus Integrated Marketing Communication. Jakarta : PT. Gramedia Pustaka Utama.

Sahin, A., C. Zehir, dan H. Kitapci, 2012, The Ef ects of Brand Experience and 
Service Quality on Repurchase Intention: The Role of Brand Relationship Quality, African Journal of Business Management, Vol. 6, No 45: 11190-11201.

Sahin, A; Zehir, C; and Kitapci, H. 2012. The Effect of Brand Experience and Service Quality on Repurchase Intention: the Role of Brand Relationship Quality. African Journal of Business Management.Vol. 6 No.45, 1119011201.

Schiffman, L. and Kanuk, L. 2010. Consumer Behavior, 7th Edition. Upper Saddle
River: Prentice Hall. Sekaran, U. and Bougie, R. 2010. Resea

Schiffman, Leon, Kanuk, Leslie Lazar and Wisenblit, Joseph. (2013). Consumer Behavior, 10 Edition, Prentice Hall, Singapore.

Sugiyono. (2013). Metode Penelitian Kuantitatif, Kualitatif dan R\&D. Bandung: Alfabeta.CV.

Sukardi. (2008). Metodologi Penelitian Pendidikan, Kompetensi dan Praktiknya. Jakarta : PT. Bumi Aksara. 
ISSN 2086-9592 